\title{
Peripheral blood markers of bacterial sepsis
}

Sri Lanka Journal of Child Health, 2010; 39: 37-38

(Key words: Peripheral blood markers, bacterial sepsis)

The diagnosis of bacterial sepsis is crucial to proper and optimal management of ill children. In certain cases infection may be obvious with several clinical and laboratory features while in others the diagnosis may be difficult, quite uncertain and not all that easily established. Although it is considered the "Gold Standard", the classical and age old investigation of cultures from possibly infected material and blood have several disadvantages such as it not being positive in a considerable proportion of cases, interference by prior antibiotic therapy and technical difficulties in its performance. These problems are especially prevalent in the developing world, a region of the world which is also one that is particularly beleaguered by various types of infective diseases. In such scenarios, there is a definite diagnostic predicament about accurately making a diagnosis of infective bacterial aetiology.

The recognition of the presence of several proinflammatory markers in the peripheral blood of patients with sepsis has led to the development of tests which can help in the diagnosis of infective diseases. Among these are the acute-phase proteins or acute-phase reactants which have been empirically defined as those whose plasma concentration changes by 25 per cent or more following inflammatory stimuli ${ }^{1}$. There are quite a number of these reactants, among which are $\mathrm{C}$ reactive protein, opsonin, serum amyloid $\mathrm{P}$ component, serum amyloid A, complement factors, mannan-binding lectin, alpha 2-macroglobulin, fibrinogen, prothrombin, factor VIII, von Willebrand factor, plasminogen, ferritin, ceruloplasmin, haptoglobin, alpha 1-antitrypsin and alpha 1-antichymotrypsin ${ }^{2}$. Several cytokines too have been assessed, including interleukin 6 (IL6), interleukin 8 (IL-8) and tumour necrosis factor alpha (TNF- $\alpha$ ). Procalcitonin has been added to this list in the early part of this century.

Of all these markers the two which have been extensively investigated and found to be most useful are C-reactive protein (CRP) and procalcitonin (PCT). In the mid 1990s, immunoassays for CRP, with greater sensitivity than those previously in routine use, revealed that increased CRP values, even within the range previously considered normal, strongly predict future coronary events. These findings triggered widespread interest, especially, remarkably, in the US, where the clinical use of CRP measurement had been largely ignored for about 30 years. CRP production is part of the nonspecific acute-phase response to most forms of inflammation, infection, and tissue damage and was therefore considered not to provide clinically useful information. Indeed, CRP values can never be diagnostic on their own and can only be interpreted at the bedside, in full knowledge of all other clinical and pathological results. However, they can then contribute powerfully to management, just as universal recording of the patient's temperature, an equally nonspecific parameter, is of great clinical utility. In the presence of sepsis, CRP rises above normal limits within 6 hours, and peaks at 48 hours. Its half-life is constant, and therefore its level is mainly determined by the rate of production ${ }^{4}$. Thus the level to which it rises is indicative of the degree of sepsis.

Procalcitonin, a protein of 116 amino acids was discovered in the 1970 s but it was only in the early 1990 s that its elevated levels in sepsis were recognised ${ }^{5}$. PCT levels are known to increase in cases of sepsis, septic shock and in severe systemic inflammatory reactions. It has an in vivo half life of 20 to 24 hours and has a high stability in serum or plasma in vitro. There is significant correlation between the levels of PCT and the severity of sepsis $^{6}$.

It has also been shown that plasma CRP and PCT levels correlate well with TNF- $\alpha$ and IL- ${ }^{7}$. Serum PCT levels show a rapid increase in children with sepsis, even in infants less than 12 month old, and they have a better prognostic value than C-reactive protein or neutrophil count ${ }^{8}$. In critically ill children PCT concentration is a better diagnostic marker of sepsis than CRP and in critically ill neonates, PCT and CRP are similar diagnostic markers of sepsis 9 . A PCT concentration higher than $8.1 \mathrm{ng} / \mathrm{ml}$ identified all children with bacterial sepsis ${ }^{9}$. Judging on the research studies available, both CRP and PCT are very useful tests in paediatrics and neonatology to differentiate sepsis from other illnesses in babies and children.

Both tests have reasonably high sensitivity and specificity. CRP reacts more slowly than PCT but is more sensitive and more non-specific than PCT in the sense that even minor inflammatory reactions can lead to a rise in CRP. In contrast, PCT rise is more rapid and more specific. PCT is particularly 
useful in recognising the Systemic Inflammatory Response Syndrome (SIRS), especially in children. In transplant rejection CRP is elevated but not PCT. Both tests are very useful, especially when the infectious focus is not obvious or has not been detected. They are of value in lung infections, particularly in Acute Respiratory Distress Syndrome (ARDS), meningitis, peritonitis and in all types of perinatal sepsis of neonates. Both tests can also be used to monitor progress, the elevated levels which fall with treatment indicating consistent improvement.

As for the situation in Sri Lanka, most unfortunately, very few, if any, of the public sector medical institutions have the facilities to perform these tests. They are available in the private sector but at considerable expense. The likely basic cost of CRP is around 400 Sri Lankan rupees while that of PCT is around 4500 rupees. These costs are calculated on the absolute quantitative methods using autoanalyzers. In contrast, the cost is likely to be much lower with semi-quantitative latex slide manual methods. However, these latter methods can provide only positive range values and not accurate real values. One could easily argue that something is better than nothing.

It is well a well recognised fact that there is some overuse of anti-bacterial drugs in the Sri Lankan paediatric scenario. In most such instances, these drugs are used in good faith in the face of uncertainties in making an accurate diagnosis of bacterial infections. Money spent on the provision of facilities for determination of CRP and PCT, tests which would be of immense value in these circumstances, is likely to repay the costs by reducing the use of unnecessary anti-bacterial therapy. Besides, with advancing progress in medicine, providing the necessary facilities for performing these tests becomes a significant development in the provision of optimal care for our children. The current evidence strongly supports a concerted request to include these tests in the diagnostic armamentaria of the state run Sri Lankan National Health Service.

\section{References}

1. Acute phase proteins - Molecular biology, biochemistry and clinical applications. Editors, Mackiewicz A, Kushner I, Baumann H. Available from:
http://books.google.com/books?id=spSqTGlP AfYC\&pg $=$ PP1\&dq $=$ acute + phase + proteins \&c $\mathrm{d}=1 \# \mathrm{v}=$ onepage $\& \mathrm{q} \& \mathrm{f}=$ false. Accessed on $04^{\text {th }}$ May 2010

2. Acute phase proteins. Wikipedia, the free encyclopaedia. Available from:

http://en.wikipedia.org/wiki/Inflammatory ma rkers. Accessed on $04^{\text {th }}$ May 2010

3. Pepys MB, Hirschfield GM. C-reactive protein : a critical update. J Clin Invest 2003; 111(12): 1805-12.

4. C-reactive protein. Wikipedia, the free encyclopaedia. Available from: http://en.wikipedia.org/wiki/Creactive protein. Accessed on $07^{\text {th }}$ May 2010

5. Maruna $\mathrm{P}$, Nedelnikova $\mathrm{K}$, Gurlich R. Physiology and genetics of procalcitonin. Physiol Res 2000; 49 (suppl.1):S57-S61.

6. Zeni F, et al. Procalcitonin serum concentrations and severity of sepsis. Clin Int Care Suppl 21994; 5:89-98.

7. Oberhoffer M, Karzai W, Meier-Hellmann A, Bogel D, Fassbinder J, Reinhart K. Sensitivity and specificity of various markers of inflammation for the prediction of TNF- $\alpha$ and IL-6 in patients with sepsis. Crit Care Med 1999; 27(9):1814-8.

8. Casado-Flores J, Blanco-Quirós A, Asensio J, Arranz E, Garrote JA, Nieto M. Serum prolactin in children with suspected sepsis: A comparison with C-reactive protein and neutrophil count. Ped Crit Care Med 2003; 4I2: 190-5.

9. Enguix A, Rey C, Concha A, Medina A, Coto D, Dieguez MA. Comparison of procalcitonin with C-reactive protein and serum amyloid for the early diagnosis of bacterial sepsis in critically ill neonates and children. Int Care Med 2001; 27:211-5.

\section{B J C Perera} Joint Editor 